\title{
Las aventuras de Alicia en el maravilloso mundo del conocimiento: el camino hacia la actual alfabetización
}

\section{Alice's adventures in the wonderland of knowledge: the path to current literacy}

Javier Sanz-Valero

Professor da Universidad de Alicante; membro do grupo coordinador de la Red de Malnutrición en Iberoamérica (Mel-CYTED) jsanz@umh.es

Universidad Miguel Hernández

Departamento de Salud Pública, Historia de la Ciencia y Ginecología

Carretera Nacional, $\mathrm{N}-332, \mathrm{~s} / \mathrm{n}$

Sant Joan d'Alacant - Alicante - España

\section{Luis David Castiel}

Pesquisador da Escola Nacional de Saúde Pública/Fundação Oswaldo Cruz; coordenador do Grupo Fiocruz (Brasil) da Red Mel-CYTED luis.castiel@ensp.fiocruz.br

\section{Carmina Wanden-Berghe}

Professora da Universidad Cardenal Herrera; coordenadora da Red Mel-CYTED

carminaw@telefonica.net

Recebido para publicação em março de 2009.

Aprovado para publicação em outubro de 2009.

SANZ-VALERO, Javier; CASTIEL, Luis David; WANDEN-BERGHE, Carmina. Las aventuras de Alicia en el maravilloso mundo del conocimiento: el camino hacia la actual alfabetización. História, Ciências, Saúde - Manguinhos, Rio de Janeiro, v.17, n.1, jan-mar. 2010, p.153-164.

\section{Resumen}

Alicia quiere estudiar con libros divertidos y llenos de dibujos de colores. El cuento de "Alicia en el país de las maravillas" sirve como excusa para introducir y discutir la importancia actual de la alfabetización digital y cómo las tecnologías de la comunicación e información han modificado la forma de trasmitir y divulgar el conocimiento. Para reflexionar, como corolario, que en la actualidad Alicia tendría acceso a un montón de bonitos documentos multimedia, de mayor o menor calidad, a través de múltiples caminos. Sin embargo, conocer su verdadero valor y aptitud es un privilegio que por su incipiente formación aún no ha alcanzado. ¡Este es su reto!

Palabras clave: alfabetización digital; acceso a la información; tecnología de la información; comunicación; hipermedia.

\section{Abstract:}

Alice wants to study with amusing books filled with colorful drawings. "Alice's adventures in Wonderland" serves as excuse to introduce and discuss the current importance of digital literacy and how communication and information technologies have changed the way of transmitting and disseminating knowledge. Considering as a corollary, Alice today would have access to a multitude of beautiful multimedia documents, of greater or lesser quality, available through multiple paths. However, given her incipient education, knowing their true worth and aptitude is a privilege she has yet to obtain. This is her challenge!

Keywords: digital literacy; access to information; information technology, communications; hypermedia. 


\section{El libro lleno de dibujo: nuevas formas de documentos}

Lewis Carroll (seudónimo con el que Charles Dodgson firmaba sus obras) en su libro Las aventuras de Alicia en el país de las maravillas creó una serie de historias en las que trata el momento, jenigmático momento!, en que la niña inicia el camino hacia el fascinante, misterioso y paradójico mundo de los adultos. Este cuento y alguna de sus adaptaciones y explicaciones (González Ruiz, 2000) van a servir de hilo conductor del presente escrito, recurriendo a algunos ejemplos para intentar explicar los embrollos que para muchas personas supone la aplicación de las nuevas tecnologías en el campo de la comunicación y la documentación.

Alicia estaba sentada en la rama de un árbol jugueteando con su mascota, un simpático gatito blanco. Debajo de la rama, su hermana mayor leía en voz alta un pasaje de un libro. La voz de la hermana sonaba monótona, autoritaria y aburrida, lo que alejaba a Alicia de la lección de historia, hasta tal punto que ya no prestaba atención y estaba centrada en los juegos con su gato. A la primera risa, la reprimenda no se hizo esperar: "La Niña, la Pinta y la Santamaría, y después de una navegación de más de dos meses por mares desconocidos, en la gloriosa mañana del 12 de octubre, descubrió el nuevo mundo, Cristóbal Colón. Ese acontecimiento conmovió profundamente a Europa, dando a Colón la gloria... ¡Alicia!", levantó la voz la hermana. "¿Sí? Estoy oyendo", se excusó Alicia. "Bien, pues prosigamos... dando a Colón la gloria de su inmortal hazaña que fue premiada por la corona de España. Los Reyes Católicos...", prosiguió la hermana (Carroll, 2003, p.6).

Mientras, Alicia, que jugaba con su gato en la rama del árbol, comenzó a reírse. "¡Alicia!, ¿quieres prestar atención a tu clase de historia?", insistió la hermana. "Ay, qué aburrido. ¿Cómo voy a poner atención si ese libro no tiene dibujos?”, dijo Alicia. “¿Dibujos?, pero qué ocurrencia. Los mejores libros que hay en este mundo no tienen dibujos", sentenció la hermana de Alicia con tono de disgusto. "En este mundo puede ser, pero en el mío, sí. En mi mundo los libros estarían llenos de dibujos", concluyó Alicia con gran convencimiento (Carroll, 2003, p.7).

Es obvio que Alicia prefiere un libro que no se ciña a formas textuales, que contenga dibujos y, ¿por qué no?, música o imágenes en movimiento. Que permita saltar de un tema a otro sin descomponer el mensaje y que conecte, enlace, con la explicación de las palabras desconocidas. Es decir, Alicia quiere estudiar mediante el uso de hipertexto, utilizando procedimientos que permitan escribir, diseñar o componer contenidos (texto, sonido, imagen, video u otros medios) y además tener la posibilidad de interactuar con otros usuarios.

Pero, ¿cuál es el objetivo? Que Alicia aprenda historia, ¿no? Pues entonces, ¿por qué no adecuarnos a ella y a su sistema de necesidades, intereses y expectativas? A ella, el hipertexto, y por su intermedio todos los elementos multimedia, le abre un camino nuevo lleno de posibilidades. Tradicionalmente la escritura se ha producido y transmitido de forma secuencial y jerárquica y los soportes sólo permitían la lectura lineal. Por el contrario, el hipertexto ofrece una nueva manera de organizar la información y esto tiene enormes repercusiones sobre la tradicional forma de concebir el documento, pero sobre todo modificando los métodos de almacenamiento y recuperación de la información en los que Internet, y más concretamente, la World Wide Web (WWW), se ha convertido en una 
especie de biblioteca total en donde es posible obtener no sólo las referencias bibliográficas y documentales requeridas, sino lo que es más importante, un acceso directo e inmediato al documento (Lamarca Lapuente, 2006, p.122-144).

La magnitud del hipertexto no está solamente en los bloques de texto, ni en la forma como están organizadas, ni en la posibilidad de recorrerlo por diferentes vías. Su capacidad radica en la llamada 'doble vía del hipertexto' (Nelson, 1992), un sistema de organización de datos y una forma de pensar: las tecnologías al servicio del conocimiento. El hipertexto es la base funcional y estructural de la WWW. Podríamos decir que la Web es un hipertexto de escala planetaria puesto que cualquier usuario puede poner su página en la red y establecer enlaces a cualquiera de los documentos disponibles allí. La Web es un sistema hipertextual preparado para recorrer diferentes páginas dispuestas en servidores accesibles desde cualquier ordenador conectado a Internet y enlazadas unas con otras conformando una estructura similar a la de la tela de araña, típicamente una red hipertextual asociativa, o mejor dicho, la red hipertextual por antonomasia. Las páginas web se enlazan unas a otras dentro de cada hiperdocumento y pueden conectarse a otros hiperdocumentos llevando al usuario de un servidor a otro sin necesidad de teclear ninguna ruta. La WWW ha triunfado $y$ millones de documentos se encuentran accesibles mediante este sistema de almacenamiento y acceso a la información, constituyendo una gran red documental de estructura hipertextual (Lamarca Lapuente, 2006, p.144-161).

Está claro que el hipertexto genera un nuevo documento que posibilita una lectura no continua, una nueva forma de enfrentarlo y aprovecharlo. Los textos, de por sí en número excesivo, permiten enlazar con nuevos contenidos generando un cúmulo de información imposible de ser asimilada en su totalidad. Asimismo, son visualizados, ¿usados?, de forma rápida, casi superficial; saltando de un fragmento a otro y asimilando pequeños trozos del mismo, generalmente fijando la atención en aquellos párrafos que están en negrita, sombreados o, como dicen los anglosajones, sobreiluminados (¿en fosforito?) dificultando poder releer los temas. Esta forma de utilizar el escrito puede parecer menos reflexiva, pero quizá permite fijar la atención en ideas puntuales. En síntesis, el actual documento digital genera una nueva forma de leer y escribir basada en aprovechar pequeños fragmentos pero que recogen los conceptos más importantes con los cuales se puede generar un nuevo documento; un compendio de las ideas fundamentales recogidas en el original. La lectura se podría denominar 'chispazo' y la escritura 'copiar y pegar'.

Es interesante dejar constancia de futuras mejoras a partir de la Web Semántica, dotando de significado a los documentos contenidos en la WWW. Esto es, la información se indiza mediante metadatos, de manera que puede ser interpretada por actores computerizados. Prima la idea de transformar la red en un espacio de conocimiento y se abre la posibilidad de localizar información mediante conceptos bien definidos.

\section{“¿Hacia dónde tengo que ir desde aquí?": del hipertexto a la transmisión del conocimiento}

"Y, ¿cómo sabes tú que yo estoy loca?", preguntó Alicia. "Has de estarlo a la fuerza, de lo contrario no habrías venido aquí", contesto el Gato de Cheshire. "¿Me podrías indicar 
hacia dónde tengo que ir desde aquí?", insistió Alicia. "Esto depende en gran parte del sitio al que quieras llegar", dijo el Gato. "No me importa mucho el sitio, siempre que llegue a alguna parte", añadió Alicia rápidamente como explicación. "Entonces tampoco importa mucho el camino que tomes: Siempre llegarás a alguna parte si caminas lo suficiente", terminó diciendo el Gato de Cheshire (Carroll, 2003, p.59-60).

Carroll al plantear estas preguntas a través de sus personajes, compartió una profunda cuestión: las dudas que se generan en el momento de la toma de una decisión. Este ejemplo se puede utilizar para discutir sobre las incertidumbres ante las nuevas tecnologías. Las tecnologías facilitan el acceso a la información, facilitando el cumplimiento de la secuencia datos - información - conocimiento. La información no es más un producto final, sino que representa una materia prima que es necesario someter a un proceso de transformación con el objetivo de extraer los conocimientos que pueden contribuir a comprehender una situación y la toma de decisiones estratégicas en un determinado campo de actividades.

Para muchas personas 'ir a lo desconocido' es propio de locos, de imprudentes aventureros que no meditan las posibles consecuencias que conlleva el 'dirigirse a alguna parte'. Con todo, hay que tener presente que tomar una decisión implica disponer de formación, cultura, conocimiento y criterio para asumir la posibilidad más conveniente. Sin estas condiciones es igual a donde se vaya, no se podrá diferenciar si se ha elegido, o no, el camino adecuado.

Actualmente, los ordenadores han entrado con gran fuerza en el mundo académico, es difícil imaginar un(a) universitario(a) paseando por el campus sin llevar en su mochila un 'portátil'. Muchos profesores recurren al PowerPoint para reforzar los conceptos teóricos o usan el correo electrónico para tutorizar a los alumnos. Incluso es usual 'colgar' los documentos docentes en el campus virtual o utilizarlo como tablón donde informar de las calificaciones. Situaciones totalmente desconocidas hace tan solo veinte años.

Sin embargo, la docencia no ha sufrido grandes cambios, en la mayoría de los casos se sigue el espíritu centenario de la clase magistral y el profesor sigue siendo el transmisor del conocimiento, el que sabe convertir la información en el producto final. Pocos docentes orientan sus enseñanzas en sentido de favorecer el 'aprender a aprender'. Su papel de depositario de todos los conocimientos debería cambiar a la de promotor de aptitudes de aprendizaje. Entender que en la sociedad global, lo grave no es desconocer una cosa, sino no disponer de la capacidad para poder adquirir este conocimiento. La verdadera docencia es la que ayuda a desarrollar habilidades y estrategias que le permitan al alumno procesar y administrar la abundancia de información.

La docencia no puede seguir representando un papel clásico, con luz tenue, donde nada cambia; no es posible seguir representando el mismo papel si ha cambiado el decorado (Esteve, 2004, p.131-166), una tramoya que se ha vuelto global y en muchos casos virtual. El escenario docente debe cambiar desde la creencia de que la formación es algo externo, 'a uno le forman', a la implicación en la adquisición de destrezas y aptitudes (Castañeda Quintero, Prendes Espinosa, 2005, p.13-15); de nuevo, 'aprender a aprender'.

Hoy en día son pocos los que ponen en duda que el documento electrónico sustituye, con ventajas, al impreso. La razón se encuentra en el incremento de información, en la rapidez de acceso en relación al espacio ocupado y en la facilidad de utilizar y copiar los 
textos en diferentes soportes con nulo coste de producción. En realidad se está ante dos cambios: el primero afecta aparentemente sólo al soporte, la pantalla sustituye al papel; el segundo afecta al mismo modo en que se organiza la información, e incluso a cómo se codifica. El primero supone cambios más profundos de los que se dejan entrever; el segundo cambio afecta de un modo decisivo al modo de trasmitir nuevo conocimiento (Bartolomé, 2004, p.215-234).

En el caso del documento hipertexto, podemos encontrarnos, aparentemente, en un contexto similar a la del escrito cuando se trata de documentos informatizados que sustituyen al papel, la situación de lectura casi no varía en cuanto a la relación de los sujetos. Pasar de la página escrita a la pantalla no supone un simple cambio de soporte para adaptarse a los gustos del día, ya que se trata de un cambio radical en la concepción de las herramientas hasta ahora utilizadas en el discurso de transmisión de conocimientos.

En este nuevo acercamiento a los textos, la dimensión de la espacialidad es dominante y la memoria debe adaptarse a este nuevo parámetro. La superposición de los documentos es la llave esencial de la individualización de la actividad. El usuario ya no tiene la referencia del espacio de la doble página (de arriba a abajo y de izquierda a derecha) sino la de un desarrollo continuo, no lineal. Con este procedimiento de superposición de datos abandona parte de su memoria a las nuevas herramientas y debe organizar, en primer lugar, una nueva memoria espacial y física, y, en segundo, aprender a ejercer una memorización de gestos relacionados con la manipulación de la pantalla (Seré, 2006).

Las nuevas tecnologías asumen lo existente hasta el momento y potencian la forma de transferir la información, pero la función final sigue siendo la misma, la transmisión de conocimientos.

Ha llegado ya el momento de sacar un partido real a la avalancha tecnológica que nos envuelve, sin soflamas revolucionarias pero también sin conformismos inmovilistas. Quizá sea tiempo de introducir nuevas técnicas que no rasguen el tejido centenario de la enseñanza. Que no rompan con los esquemas docentes actuales pero que no los trasladen al mundo electrónico, sino que los hagan avanzar, despacio, hacia modelos diferentes.

En la docencia actual coexisten comportamientos muy diferenciados. Por un lado persiste un aprendizaje de sesgo presencial y clásico, basado en el aula convencional y la comunicación oral; por otro, aparecen corrientes más experimentales que privilegian la flexibilidad y la autonomía, donde se encuentran los materiales en red, las tutorías en línea, el acceso online a las bibliotecas, y se emplean todos los potenciales multimedia que ofrece la WWW. De hecho es fácil detectar, en el ámbito universitario, movimientos e iniciativas que tratan de sacar partido de nuevos conceptos o modelos que renuevan o reformulan sus funciones más clásicas. Y en este estado de cosas, propuestas como la teleformación o las ofertas formativas e investigadoras en red, en otras muchas, son una clara referencia en estos momentos.

Internet ha modificado la docencia representando una escala hacia la autonomía de aprendizaje y la certificación del pluriculturalismo; pero también siembra una inquietud humanística al constatar una progresiva pérdida del aprendizaje grupal que hay que saber integrar (Villar Angulo, 2004, p.63-67). 
Ahora bien, la gran ventaja de la implantación y evolución de las tecnologías de la información, para sosiego de los más conservadores, es la complementariedad y acumulación, no la de sustitución. Pero, hoy por hoy, las info-cogno-tecnologías afectan a todas nuestras estructuras sociales y a todos nuestros conciudadanos en sus distintos ámbitos de desarrollo; la lectura o los conceptos matemáticos, el arte y la cultura, la mejora de nuestras capacidades personales no son hoy posible sin la contribución de las estas tecnologías y por tanto su dominio forma parte ya de las competencias básicas. Es ya un tópico señalar que la consulta del correo electrónico, el uso de la telefonía móvil o de la banca digital, requiere la adquisición de unas mínimas habilidades técnicas sin las cuales se cae en una especie de exclusión (Sanz-Valero, 2008, p.119-126). Para un profesional, en el maremágnum de información que maneja hoy en día cualquier institución, dominar los métodos y las herramientas que sirven para discernir lo que es realmente útil se ha convertido en una de las habilidades más demandadas en el mundo laboral. Esta precariedad del exceso contrasta con la frágil formación de una gran mayoría de personas (Castiel,Vasconcellos-Silva, 2006, p.25-59).

Por ende, el avance hacia la sociedad del conocimiento implica, junto con el desarrollo de las capacidades instrumentales y de aprendizaje permanente, planteamientos de nuevas implicaciones educativas.

\section{“¿Celebrar el no cumpleaños?": algo ha de cambiar para conseguir la plena alfabetización}

Ya se lo había advertido el Gato de Cheshire: "Por ahí, le había dicho a Alicia, vive un Sombrerero y en esa otra dirección, una Liebre Marcera... . Da igual al que visites... ¡Los dos están igual de locos!".

"Bien sabido es que tienes tú un cumpleaños", aseguró el Sombrerero Loco. "imagínate! Uno solamente al año", dijo con énfasis la Liebre de Marzo. "¡Aaaaaah!... Pero te quedan 364 días de no cumpleaños”, exclamó el Sombrerero. “iPrecisamente, son los que celebramos aquí!", exaltó la Liebre. "Entonces, preguntó tímidamente Alicia también es mi no cumpleaños hoy". "¿De veras? Ay, qué pequeño es este mundo", preguntó sorprendido el Sombrerero. "En tal caso... comenzó a cantar la Liebre, ¡Feliz, feliz no cumpleaños! ¿A mí? ¡A tú! ¡Feliz, feliz no cumpleaños! ¿Para mí? ¡Para tú!...” (Carroll, 2003, p.63-73).

Poco antes, Alicia ya se había tropezado con otro personaje que encarna el conservadurismo, que tanto gustaba a Carroll. La Oruga fue la primera en hablar. "¿Qué tamaño te gustaría tener?", le preguntó. "No soy difícil en asunto de tamaños", se apresuró a contestar Alicia. "Sólo que no es agradable estar cambiando tan a menudo, sabe". "No sé nada", dijo la Oruga. Alicia no contestó. Nunca en toda su vida le habían llevado tanto la contraria, y sintió que se le estaba acabando la paciencia. "¿Estás contenta con tu tamaño actual?", preguntó la Oruga. "Bueno, me gustaría ser un poco más alta, si a usted no le importa. ¡Siete centímetros es una estatura tan insignificante!", protestó Alicia. "¡Es una estatura perfecta!", dijo la Oruga muy enfadada, irguiéndose cuan larga era (medía exactamente siete centímetros). “¡Pero yo no estoy acostumbrada a medir siete centímetros!”, se lamentó la pobre Alicia con voz lastimera, mientras pensaba para sus adentros: “¡Ojalá estas criaturas 
no se ofendieran tan fácilmente!". "Ya te irás acostumbrando", dijo la Oruga, y volvió a meterse la pipa en la boca y empezó otra vez a fumar. Esta vez Alicia esperó pacientemente a que se decidiera a hablar de nuevo. Al cabo de uno o dos minutos la Oruga se sacó la pipa de la boca, dio unos bostezos y se desperezó. Después bajó de la seta y empezó a deslizarse por la hierba, al tiempo que decía: "Un lado te hará crecer, y el otro lado te hará disminuir". "Un lado ¿de qué? El otro lado ¿de qué?", se dijo Alicia para sus adentros. "De la seta", dijo la Oruga, como si la niña se lo hubiera preguntado en voz alta. Y al cabo de unos instantes se perdió de vista (Carroll, 2003, p.46-51).

Hay quien quiere celebrar constantemente el 'no cumpleaños', el defender una postura de rechazo a la tecnología como generadora de cambios. Otros, o los mismos, se conforman con medir siete centímetros. Pero, a Alicia, que quiere tener claro el fin del cambio, lo que le molesta es estar dubitativa a cada momento y no encontrar la razón que justifique la mudanza. Landow (1995) llega a la conclusión de que estas exclusiones son una muestra de la fobia por la técnica del humanista corriente. Es muy posible que detrás de las posiciones de rechazo y promoción de las nuevas tecnologías se esconda una lucha por el poder: resistir a la tecnología podría favorecer un status quo jerárquico y conservador, mientras que promoverla, podría estar indicando cierta posibilidad de emancipación. ¿Pero es la cara del poder contemporáneo tan clara como para aceptar que un optimismo tecnológico es suficiente para allanar el camino hacia esa democratización cultural que espera Landow?

A estas alturas resulta gastado certificar que las tecnologías de la información y la comunicación tienen importantes consecuencias y poderosos efectos sobre el desarrollo social, económico y cultural de nuestras sociedades. Asimismo, también parece existir acuerdo en que la educación en general, y de modo más específico la formación o alfabetización tecnológica, del conjunto de los individuos y colectivos humanos, es una condición necesaria para el avance y el desarrollo de la llamada sociedad del conocimiento. Estas ciencias aplicadas han tenido un fuerte impacto en los campos de la educación, de la investigación y de la difusión de los conocimientos. Ahora bien, convivir en esta sociedad requiere de actitud, conocimiento, competencia y habilidad en el manejo de sus técnicas para poder beneficiarse de ellas. Este desarrollo impetuoso de la ciencia y la técnica, acentuado en la segunda mitad del siglo XX, ha revolucionado todas las esferas del saber.

La actividad científico-informativa no escapa a tales transformaciones y en ella las nuevas tecnologías han significado, entre otras cosas, la optimización de los procesos técnicos y de los servicios. Las infotecnologías han cambiado las reglas del juego de los procesos formativos tradicionales. En consecuencia, la alfabetización informacional (Alfin) no ha de ser considerada como un añadido al resto de los procesos característicos de la educación formal, sino como un eje transversal a lo largo y ancho del currículo formativo.

Meador (1997), hace más de diez años, pronosticó que una persona educada debería poseer una alfabetización múltiple, consistente en disponer de cultura literal (capacidad para leer textos escritos); cultura numérica (capacidad para leer cifras y cuadros); cultura informática (capacidad para usar las aplicaciones elementales de un ordenador cada vez más complejos); cultura gráfica (capacidad para entender gráficos) y cultura informacional - alfabetización informacional - (capacidad para reconocer cuándo se necesita información y tener la habilidad para localizar, evaluar y utilizar eficientemente la información requerida, 
lo que le permite llegar a ser un aprendiz independiente a lo largo de la vida) (Campal García, 2006, p.49-55). Es decir, la formación necesaria para moverse por la actual sociedad del conocimiento.

En ella, siendo necesarios los aparatos, no constituyen la esencia de la Alfin, como tampoco lo es la enseñanza mecánica de habilidades y destrezas. Los soportes y el adiestramiento son elementales, solamente son el primer escalón del proyecto educativo enfocado hacia la gestión del conocimiento. Quien ignore la obra de Cervantes no la va a conocer por mucho que disponga de un ordenador de última generación, y quien desconozca las canciones de Joaquín Sabina o de Vinicius de Moraes, no descubrirá los mensajes que contienen las letras del primero, ni imaginará la belleza de Ipanema y su Garota, como canta la Bossa Nova del segundo, por mucho que disponga de acceso de banda ancha y sea experto en el manejo de e-Mule. No es solo saber pulsar las teclas, Alfin va más allá de un proceso individual de adiestramiento. Se podría decir, sin miedo a equivocarse, que es necesario entrar en el concepto educativo de 'aprender a aprender'. Es decir, reinterpretar la frase atribuida a Albert Einstein cuando decía que "la educación es aquello que permanece cuando uno ha olvidado todo lo aprendido en la escuela".

Bunk (1994) clasifica la competencia profesional atendiendo a cuatro tipologías básicas del conocimiento, ¿capacidad?. Posee 'competencia técnica' aquel que domina como experto las tareas y contenidos de su ámbito de trabajo y los conocimientos y destrezas para ello. Posee 'competencia metodológica' aquel que sabe reaccionar aplicando el procedimiento adecuado a las tareas encomendadas y a las irregularidades que se presenten, que encuentra de forma independiente vías de solución y que transfiere adecuadamente las experiencias adquiridas a otros problemas de trabajo. Posee 'competencia social' aquel que sabe colaborar con otras personas de forma comunicativa y constructiva y muestra un comportamiento orientado al grupo y un entendimiento interpersonal. Posee 'competencia participativa' aquel que sabe participar en la organización de su puesto de trabajo, es capaz de organizar y decidir, y está dispuesto a aceptar responsabilidades. La integración de estas cuatro competencias parciales da lugar a la 'competencia de acción', que es en rigor indivisible.

En esta línea, concepto de competencia, el Informe Delors (Unesco, 1996) basa el aprender a aprender, cómo aprender a saber, aprender a hacer, aprender a estar y aprender a ser. Significa que la persona ha desarrollado habilidades y estrategias que le permiten procesar y administrar información. Es decir, las habilidades para aprender a aprender como: "Utilización de técnicas y procedimientos que permiten a quien los domina la autonomía intelectual, en el sentido de que hacen posible el aprendizaje autónomo e intencional en situaciones formales e informales de estudio" (Unesco, 1996, p.17).

Queda patente que las tecnologías de la información son actualmente necesarias y una excelente herramienta para favorecer la difusión y la democratización del conocimiento ser cultos para ser libres. Además esta producción y permeabilidad del conocimiento se puede realizar a un bajísimo coste. Hoy, el valor se genera en habilidades y formas de concebir y transmitir conocimiento: info-cogno-tecnologías. La formación en estas tecnologías es un pilar fundamental del sistema productivo. Sin esta formación, tanto la brecha digital como social, están servidas (García Dotor, 2006). La característica que más profundamente distingue el modelo de sociedad que se viene perfilando en la actualidad, la 'sociedad del conocimiento', 
es el acceso universal, masivo, intensivo y permanente a los conocimientos existentes y a los que se van generando (Ávalos Gutiérrez, 2005, p.22-39).

Se considera que estamos viviendo en directo la tercera revolución industrial, pero ocurre que, como somos protagonistas activos, no somos plenamente conscientes de su alcance. Esta falta de matiz hace que no se evalúe suficientemente la importancia y los impactos de esta suerte de revolución tecnológica. Dentro de unos años, cuando se tenga una mayor perspectiva histórica, se verá con mayor claridad.

En consecuencia, el conocimiento como consecuencia del aprendizaje se nos presenta como la herramienta fundamental para poder afrontar el momento presente. Conocimiento para evaluar, conocimiento para decidir, conocimiento para actuar. El conocimiento se presenta como la 'llave de oro' que abre las puertas, pequeñas o grandes, que permiten acceder e integrarse en el mundo tecnológico. Una 'llave de oro' conseguida mediante formación, criterio, cultura y conocimiento (Martínez Sánchez, 2004, p.195-215).

\section{“¡Dios mío! ¡Voy a llegar tarde!”: nuevo concepto de espacio y tiempo}

Volvamos al principio de la historia y retomemos un camino diferente, ¿o quizá el mismo? Reflexionemos más allá del nuevo documento.

Alicia empezaba ya a cansarse de estar sentada con su hermana a la orilla del río, sin tener nada que hacer: había echado un par de ojeadas al libro que su hermana estaba leyendo, pero no tenía dibujos ni diálogos. "¿Y de qué sirve un libro sin dibujos ni diálogos?", se preguntaba Alicia. Así pues, estaba pensando (y pensar le costaba cierto esfuerzo, porque el calor del día la había dejado soñolienta y atontada) si el placer de tejer una guirnalda de margaritas la compensaría del trabajo de levantarse y coger las margaritas, cuando de pronto saltó cerca de ella un Conejo Blanco de ojos rosados. No había nada muy extraordinario en esto, ni tampoco le pareció a Alicia muy extraño oír que el conejo se decía a sí mismo: “¡Dios mío! ¡Dios mío! ¡Voy a llegar tarde!” (Cuando pensó en ello después, decidió que, desde luego, hubiera debido sorprenderla mucho, pero en aquel momento le pareció lo más natural del mundo). Pero cuando el conejo se sacó un reloj de bolsillo del chaleco, lo miró y echó a correr, Alicia se levantó de un salto, porque comprendió de golpe que ella nunca había visto un conejo con chaleco, ni con reloj que sacarse del chaleco, y, ardiendo de curiosidad, se puso a correr tras el conejo por la pradera y llegó justo a tiempo para ver cómo se precipitaba en una madriguera que se abría al pie del seto. Un momento más tarde, Alicia se metía también en la madriguera, sin pararse a considerar cómo se las arreglaría después para salir (Carroll, 2003, p.9).

El conejo blanco decide ir más rápido tras consultar su reloj. En la actualidad todo parece fugaz. Podemos transmitir la información instantáneamente a lugares muy alejados físicamente, mediante las denominadas 'autopistas de la información'. También es cierto que estas tecnologías son actualmente un medio rápido y fiable para obtener información desde cualquier lugar. Pero, los documentos parecen provenientes del espacio, del ciberespacio, debido a que la información proviene de un espacio virtual, no real, que no asume las características físicas del objeto utilizado para su almacenamiento, adquiriendo 
ese grado de inmediatez e inmaterialidad. Incluso el tiempo, entendido como organizador vital y medida que rige el ritmo de las personas, se torna en un nuevo concepto.

Quién sabe si el concepto de realidad virtual deba ser repensado y requiera de un examen más detenido. Internet puede convertir lo que hasta hoy considerábamos como real, concreto y material, en real, no concreto e inmaterial. El espacio Red puede considerarse un espacio no físico, pero en el que podemos interactuar, encontrarnos e incluso entablar relaciones de amistad o que generan mayores sentimientos. Aparte de postularse como un lugar donde generar y trasmitir conocimiento (Schlemmer, Backes, 2008; Trein, Schlemmer, 2009). No hay más que mirar, por ejemplo, lo que ocurre en las tecnologías de metaverso como Second Life y Eduverse, donde se ha creado un mundo virtual digital, representados en 3D (MDV3D), y en el que, a través de la creación de avatares (representaciones humanas en el mundo gráfico/digital), se puede interactuar utilizando el lenguaje textual, oral, gráfico y gestual. Así, el espacio virtual adquiere 'existencia' digital, ¿virtual?, aunque de momento no física/no material.

En nuestros días, es posible actuar en la Red desde espacios diferentes en horarios diferentes. Dos personas pueden coincidir en un espacio no físico, ¿inexistente?, en dos momentos horarios disímiles y desde dos lugares diferentes. ¿Trastoca este hecho el hasta ahora inseparable trinomio acción/espacio/tiempo? Si consideramos cada uno de los elementos del trinomio por aparte, observaríamos que el tiempo, sin espacio, sería pura duración, como la música; el espacio, sin tiempo, seria inmovilidad, como la pintura o la escultura. Pero sin tiempo y sin espacio, la acción no podría desarrollarse, ¿o en lo virtual sí?

Medir el tiempo es fascinante porque estamos midiendo un concepto, algo que al medirse inmediatamente deja de existir. Nunca la hora que decimos es precisa porque jamás nos detenemos. Aún así se han construido maravillosos relojes, como el Corpus Clock que adorna la fachada del nuevo edificio de la Biblioteca de Cambridge, para poder medir el tiempo con extrema exactitud. Este reloj, que presenta en su parte superior un ser mecánico, bautizado como Cronófago, devorador de tiempo, nos recuerda que el tiempo perdido nunca será recuperado, pero irónicamente su interesante diseño nos puede hacer perder las horas simplemente admirando su movimiento.

Además, la preocupación por medir el tiempo, por tener una medida común que permita coincidir en un momento determinado en la Red, no es nueva. En octubre de 1998, la compañía Swatch, empresa situada en Biel (Suiza) y fabricante de relojes, decretó un nuevo meridiano de referencia y, por tanto, punto de partida universal de un nuevo sistema de control del tiempo, pretendiendo ser el patrón horario para sincronizar reuniones en Internet. Este sistema de medición de tiempo está basado en pulsaciones, y su uso implica que, por una parte, no existen zonas horarias y, por otra, que desaparecen los límites geográficos. Divide el día en mil pulsos y cada pulso (que dura un minuto y 26,4 segundos) se representa por una arroba (@) y tres dígitos numéricos. Así, la primera hora (equivalente a las 12 de la noche en el meridiano de Biel), equivale a @000 hora de Internet; las 12 del mediodía son las@500 etc. Pero, esta propuesta y otras similares no explican la sensación de 'vivir en presente' que aporta la Red.

Bajtín (1989, p.237-409) extrapola de la física el carácter indisoluble del espacio y el tiempo. Desde esta perspectiva define 'cronotopo' como la conexión esencial de las relaciones 
temporales y espaciales asimiladas a la literatura, donde el espacio es entendido y medido a través del tiempo. Como en una obra de teatro, la temporalidad de la acción permanece como elemento de referencia común para los actores y espectadores, de nuevo puede extrapolarse a lo que sucede en Internet. ¿Quizá debamos hablar del cronotopo virtual?

En la Red, el tiempo se torna subjetivo, la percepción del tiempo es relativa, propio de cada individuo y ligado a variaciones de su flujo y sus pausas, quizá como intérprete del teatro Internet. Donde el 'espacio' virtual es el escenario donde se encuentran en un 'tiempo' determinado los protagonistas de la 'acción'. Quizá las personas, ¿actores?, que intervienen en la Red sean avatares de una segunda vida virtual coexistente, en directo, con la vida real. Por tanto, emulando a Bajtín (en el sentido de imitar las acciones de otro, procurando igualarlas e incluso excederlas y no en el sentido de usuarios de eMule) podríamos denominar a esta nueva conjunción del trinomio acción/espacio/tiempo como Crononet.

\section{Corolario}

En el mundo del conocimiento, Alicia tendría acceso a un montón de bonitos documentos multimedia, de mayor o menor calidad, a través de múltiples caminos. Sin embargo, conocer su verdadero valor y aptitud es un privilegio que por su incipiente formación aún no ha alcanzado. ¡Este es su reto!

\section{AGRADECIMIENTOS}

A Ignacio Sanz por compartir multitud de veces su pasión por este maravilloso cuento. Sus dudas y sus preguntas, junto con las de Alicia, inspiraron este trabajo.

\section{REFERENCIAS}

ÁVALOS GUTIÉRREZ, Ignacio. Perspectivas en la sociedad del conocimiento en América Latina. En: Cadenas, José María (Comp.). Ciencia y tecnología en América Latina: una mirada desde Venezuela. Caracas: Centro de Estudios de América, Universidad Central de Venezuela. p.22-39. 2005.

BAJTÍN, Mijail.

Las formas del tiempo y el cronotopo en la novela: ensayos sobre poética histórica. En: Bajtín, Mijail; Cazcarra, Vicente; Kriúkova, Helena. Teoría y estética de la novela. Madrid: Taurus. p.237-409. 1989.

BARTOLOMÉ, Antonio. Aprendizaje potenciado por la tecnología: razones y diseño pedagógico. En: Martínez Sánchez, Francisco; Prendes Espinosa, M. Paz (Ed.). Nuevas tecnologías y educación. Madrid: Pearson Educación. p.215-234. 2004.

BUNK, Gerard.

La transmisión de competencias en la formación y perfeccionamiento profesionales de la RFA. Revista Europea de Formación Profesional, Tesalónica, n.1, p.8-14. 1994.

CAMPAL GARCÍA, María Felicidad.

Practicando ALFIN: ALFIN de la A a la Z. Educación y Biblioteca, Madrid, v.18, n.156, p.49-55. 2006.

\section{CARROLL, Lewis}

Alicia en el país de las maravillas. Madrid: Ediciones del Sur. 2003.

CASTAÑEDA QUINTERO, Linda; PRENDES ESPINOSA, María Paz.

Tecnologías de la información y la comunicación en la enseñanza superior: análisis de una experiencia de implementación en la Universidad de Murcia. Murcia: Instituto de Ciencias de la Educación, Universidad de Murcia. 2005.

CASTIEL, Luis David; VASCONCELLOS-SILVA, Paulo Roberto.

Precariedades do excesso: informação e comunicação em saúde coletiva. Rio de Janeiro: Editora Fiocruz. 2006. 
ESTEVE, José.

El paradigma personal: influjo del trabajo profesional en la personalidad del educador. En: Escudero, Juan Manuel; Ballester, Francisco; Visedo, José Miguel (Ed.). Programa y documentos bibliográficos de formación y actualización de la función pedagógica. Murcia: Universidad de Murcia. p.131-166. 2004.

GARCÍA DOTOR, María Dolores.

La sociedad de la información en España. En: Fernández Beaumont, José (Comp.). Claves de la alfabetización digital. Madrid: Fundación Telefónica; Editorial Ariel. p.37-43. 2006.

GONZÁLEZ RUIZ, Jorge.

La página de Lewis Carroll. Disponible en: http://mural.uv.es/jorgon/alicia.htm. Acceso en: 8 feb. 2009. 2000.

LAMARCA LAPUENTE, María Jesús. Hipertexto: el nuevo concepto de documento en la cultura de la imagen. Disertación (Doctorado) - Facultad de Ciencias de la Información, Universidad Complutense, Madrid. 2006.

LANDOW, George.

Hipertexto: la convergencia de la teoría crítica contemporánea y la tecnología. Barcelona: Paidós. 1995.

MARTÍNEZ SÁNCHEZ, Francisco.

Alicia en el país de las tecnologías. En: Martínez Sánchez, Francisco; Prendes Espinosa María Paz. Nuevas tecnologías y educación. Madrid: Pearson Educación. p.195-215. 2004.

MEADOR, Karen.

Creative thinking and problem solving for young learners. New York: Teacher Ideas Press. 1997.

NELSON, Theodor.

Literacy machines 93.1. Sausalito: Mindful Press. 1992.
SANZ-VALERO, Javier.

Comunicación y documentación científica en la era digital: introducción a la alfabetización digital. En: Bernabeu Mestre, José et al. Investigación e innovación tecnológica en la Ciencia de la Nutrición: el abordaje de la malnutrición en el contexto de la cultura científica. Alicante: Editorial Club Universitario. p.119-126. 2008.

SCHLEMMER, Eliane; BACKES, Luciana. Metaversos: novos espaços para construção do conhecimento. Revista Diálogo Educacional, Curitiba, v.8, n.18, p.519-532. 2008.

SERÉ, Arlette.

El documento hipertexto en el discurso de transmisión de conocimientos. Disponible en: http://elies.rediris.es/elies24/sere.htm. Acceso en: 8 feb. 2009. 2006.

TREIEN, Daiana; SCHLEMMER, Eliane. Projetos de aprendizagem baseados em problema no contexto da Web 2.0: possibilidades para a prática pedagógica. Revista E-Curriculu, São Paulo, v.4, n.2, p.1-20. 2009.

\section{UNESCO.}

Organización de las Naciones Unidas para la Educación, la Ciencia y la Cultura. Comisión Internacional sobre la Educación Para el Siglo XXI. La educación encierra un tesoro [Informe Delors]. Paris: Ediciones Unesco. 1996.

VILLAR ANGULO, Luis Miguel.

Cuestiones tecnológicas de difusa frontera. En: Martínez Sánchez, Francisco; Prendes Espinosa, M. Paz (Ed.). Nuevas tecnologías y educación. Madrid: Pearson Educación. p.63-67. 2004.

\section{$\rightarrow \rightarrow \rightarrow<<<$}

